NOTE

\title{
Can oceanic foams limit global warming?
}

\author{
J. R. G. Evans ${ }^{1, *}$, E. P. J. Stride ${ }^{2}$, M. J. Edirisinghe ${ }^{2}$, D. J. Andrews ${ }^{2}$, R. R. Simons ${ }^{3}$ \\ ${ }^{1}$ Department of Chemistry, University College London, 20 Gordon Street, London, WC1H 0AJ, UK \\ ${ }^{2}$ Department of Mechanical Engineering, University College London, Torrington Place, London, WC1E 7JE, UK \\ ${ }^{3}$ Department of Civil, Environmental and Geomatic Engineering, University College London, Chadwick Building, \\ Gower Street, London, WC1E 6BT, UK
}

\begin{abstract}
When the diverse methods proposed for solar radiation management are surveyed, a relatively simple, environmentally acceptable, double-acting mechanism for increasing the earth's albedo emerges. It is a low-level environmental intervention that enhances a mechanism already active in nature by increasing the foam fraction of the ocean surface. Bubble rafts increase the optical reflectivity of the ocean and when bubbles burst, they launch seasalt particles that loft and increase the number concentration of cloud droplets in the marine boundary layer, thus increasing the reflectivity of stratocumulus. A strategy based on recent research for producing microbubbles appears to be the best option for large-scale use.
\end{abstract}

KEY WORDS: Ocean albedo $\cdot$ Foam $\cdot$ Bubble generation $\cdot$ Cloud brightening Resale or republication not permitted without written consent of the publisher

\section{INTRODUCTION}

Interventions to oppose climate change by geoengineering are likely to be complex and costly because the engineering scales involved are so large. It can be argued that the vaster the scale of an engineering undertaking, the simpler should be the mechanism. Solar radiation can be interrupted at different levels: in space, in the stratosphere, or by changes to optical depth of cloud or to planetary surface reflectivity. These choices need critical assessment.

Geoengineering is on the agenda because there is concern that anthropogenic causes of climate change will not be mitigated by carbon capture, the provision of non-fossil energy sources, or by demand reduction in time to prevent loss of arctic ice and emergence of methane from, inter alia, melting of permafrost. Furthermore, non-anthropogenic causes of global warming have no other source of remediation other than through natural terrestrial or solar processes. Some method of climate forcing may be needed to prevent serious threats to health (Costello et al. 2009) and, in a US report, to national security (Sullivan et al. 2007), justifying, at least, the scientific discussion of climate engineering on an international basis.

\section{STRATEGIES}

Proposed interventions have been reviewed by Teller et al. (1997), Keith (2000), and more recently by others (Morton 2007, Bala 2009). Papers from a recent meeting of the Royal Society on geoengineering are prefaced with an overview by Schneider (2008). A more recent report from the Royal Society (Shepherd 2009, p. 24) notes rather pessimistically that '... the oceans have low albedo (about 0.1) which would be difficult to change.' We suggest that this may be one of the easiest changes to effect. The following techniques have been suggested so far. Sunlight could be deflected by space mirrors situated at the L1 Lagrange point (Early 1989, Seifritz 1989). Nobel laureate Crutzen's (2006) suggestion is to inoculate the stratosphere with sulphur compounds to mimic the forcing effects of volcanic activity, a suggestion that first surfaced in 1982 (Budyko 1982). Teller et al. (1997) proposed to inject dielectric powders such as $100 \mathrm{~nm}$ alumina into the stratosphere to scatter light, or to loft semi-metallised balloons or meshes. Bower et al. (2006) and Latham et al. (2008) have suggested a plan to augment the tropospheric burden of cloud concentration nuclei (CCN) by injection of seasalt into the marine boundary layer. In 1965 there 
was a proposal to float buoyant reflective particles on the sea (Keith 2000). Others have modelled the effects of changing the albedo of human settlement and grassland (Hamwey 2007).

One of the softest albedo interventions is prompted by the work of Twomey (1971) on the relation between droplet size, concentration and reflectivity of clouds. Latham et al. (2008) proposed a method of climate forcing that involves spraying fine droplets of seawater into the troposphere. This has been developed into an engineering proposal by Salter et al. (2008). It is a forgiving strategy; if unwanted effects arise, seasalt is rained out in about $0.5 \mathrm{Ms}$, whereas additions to the stratosphere may reside for $120 \mathrm{Ms}$, to be augmented by unpredictable levels of volcanic particle injection. There are no issues of military abuse that may attend the deployment of space parasols. Nor is there danger to air traffic corridors resulting from metallised balloons or mineral powder losing height. In order to combat a $5^{\circ} \mathrm{C}$ global temperature rise it would be necessary to lift up to $30 \mathrm{Mg} \mathrm{s}^{-1}$ seawater in addition to the $300 \mathrm{Mg} \mathrm{s}^{-1}$ lofted by the oceans (Jaenicke 1993). The spray technology proposed by Latham et al. (2008) and Salter et al. (2008) involves a large number of sizable sea-going, windpowered vessels in which filtered seawater is pumped through sub-micron holes etched in silicon wafers. The aim is not to nucleate new cloud but to increase the number concentration of droplets in existing cloud regions so that reflectivity to incoming shortwave radiation is increased. A narrow droplet size distribution is needed to inhibit Ostwald ripening of droplets and to preserve the stability of cloud cover against rain-out. The challenge is to prevent droplet coagulation and hence coarsening of the sprayed droplet distribution in the plume, for which electrostatic charging of droplets is proposed.

\section{FOAMING}

With this in mind, the double-acting intervention of creating oceanic foam to increase ocean surface albedo and coincidently increase the albedo of marine stratocumulus cloud appears to have advantages. It builds on existing natural processes and is simplistic and cost effective. It is easy to incorporate feedback control and the foaming process is quickly arrested. And it is probably one of the most environmentally forgiving of the many exciting proposals currently being debated. Fig. 1 illustrates the large differences between albedos of ocean ( 0.05), rock (0.01), grassland (0.15 to 0.25 ) and oceanic foam (0.4 to 0.6$)$. One can view the foam as compensating optically for the loss of arctic ice; placed in equatorial regions, oceanic foam would increase its areal efficiency.

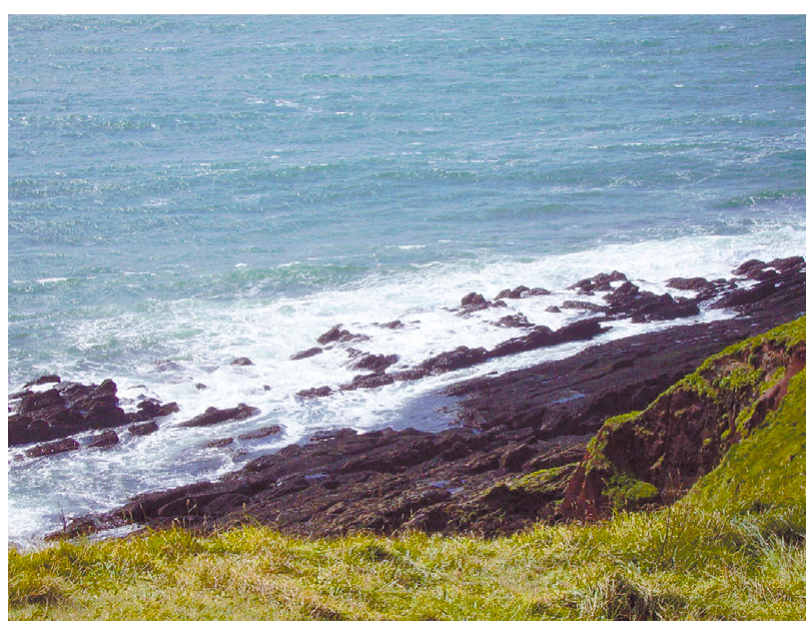

Fig. 1. Photo illustrating the variation in albedo with surface type: ocean ( 0.05), rock ( 0.01), grassland $(0.15$ to 0.25$)$ and oceanic foam (0.4 to 0.6$)$

In high winds, the crests of waves break and form froth $_{i}$ these are known as whitecaps. The planetary cooling effect of whitecaps and artificial foams has been mentioned by several authors (Whitlock et al. 1982, Koepke 1984, Frouin et al. 1996, Kokhanovsky 2004). The foam does 2 important things. It increases the reflectivity of the ocean surface, which contributes to the increase of planetary albedo in low cloud conditions. Then, as each bubble bursts, seasalt droplets are ejected into the lower atmosphere which loft, dry, are transported downwind and become active as $\mathrm{CCN}$. They increase the number concentration of cloud droplets which increases the albedo of marine stratocumulus clouds. The effect of increasing oceanic foam is therefore double-acting in terms of climate forcing by increasing albedo of either ocean or cloud. The former requires long bubble life and is needed in clear sky conditions, the latter requires short bubble life and is needed in cloudy conditions. Thus the possibililty to control bubble lifetime, informed by satellite, is desirable.

The oceans yield $10 \mathrm{Pg} \mathrm{yr}^{-1}$ of seasalt particles (Jaenicke 1993), but there is a strong meridional variation (Heintzenberg et al. 2000). Size distribution measurements for all maritime aerosols show particles from $5 \mathrm{~nm}$ to $100 \mu \mathrm{m}$ (O'Dowd et al. 1997) and those larger than about $250 \mathrm{~nm}$ are activated as CCN. Nature very effectively generates and lofts these quantities by bubble burst from marine whitecaps, whose area fraction depends on wind speed. The process of bubble burst has been expertly modelled (Boultan-Stone \& Blake 1993). As each bubble bursts, 2 types of droplets are generated: film drops and jet drops. Film drops result from the rupture of the thin upper film of the bubble and produce 10 to 100 droplets with a distribution of 
diameters that peaks at $100 \mathrm{~nm}$. These are easily lofted even at low wind speeds. Jet drops of diameter about one-tenth of the bubble diameter are produced as the bowl retracts under surface tension. The effect of surfactants on these size distributions has also been experimentally determined (Sellegri et al. 2006).

The albedo of the ocean surface varies with angle of solar incidence; it is $<0.05$ around $12: 00 \mathrm{~h}$ and remains $<0.1$ until the solar elevation angle falls to below $25^{\circ}$ (Davies 1962). These results are confirmed by Jin et al. $(2004,2002)$ who provided ocean albedo values against the cosine of solar zenith angle (SZA); albedo falls below 0.1 at $65^{\circ}$ (equivalent to Davies' $25^{\circ}$ elevation). Maximum albedo is reached at SZA $84^{\circ}$ and varies between 0.2 and 0.3. Payne (1972) gives oceanic albedo as 0.03 rising to 0.45 at SZA $>80^{\circ}$. So there is good agreement that oceanic albedo is 0.03 to 0.05 and rises only at high SZAs.

Experimentally measured values of albedo for water foams vary from 0.4 to 0.6 in the wavelength region of 0.4 to $1.0 \mu \mathrm{m}$, decreasing to 0.1 at $2 \mu \mathrm{m}$ (infrared) (Whitlock et al. 1982), possibly facilitating longer wave outward radiation at night. The significance of the effect of surface foam on planetary albedo is confirmed by Gordon \& Jacobs (1977) as a function of wind speed.

Andreas \& Monahan (2000) identify 2 types of whitecap: Type A emerge from spilling wave crests and have a high concentration of bubbles of wide size distribution; Type B are the dissipating remains of Type A with a narrow size distribution. The area fraction of ocean covered by foam, $W$, is roughly proportional to the wind speed, $U$, measured at $10 \mathrm{~m}$ height, raised to the third power:

$$
W_{\mathrm{A}}=3.16 \times 10^{-7} U^{3.2} \text { and } W_{\mathrm{B}}=3.84 \times 10^{-6} U^{3.41}
$$

Thus at a wind speed of $10 \mathrm{~ms}^{-1}, 0.05 \%$ of the ocean surface is covered by Type A and $1 \%$ by Type B whitecaps.

There is clearly scope to increase these fractions at lower wind speeds. Perhaps the simplest approach, prima facie, would be to enhance a process already taking place by positioning marine structures which could, it is believed, be designed to cause the spillage of wave crests and convert wave energy directly into the surface energy of foam bubbles. Waves could perhaps be persuaded to break at sea by modifying local countercurrents. There are serious engineering issues of anchorage, which is probably only possible in shallow continental shelf regions, which, coupled with the current uncertainty of the best global positioning, counsel in favour of mobile towed barrages. A possible low energy option to tow the barrages in deep waters might be the use of the Flettner rotor wind-powered vessels with such propulsors on the lines of those proposed by Salter et al. (2008) or the Wingsail device (Daif et al. 1991).
An alternative approach would be to modify merchant ship propulsion to produce more cavitation or to provide an incentive for ship operators to tow devices which enhance bubble entrainment in their foaming wake. The assessment would need to consider the additional fuel consumption and area and persistence of the foaming wake. The number of merchant ships in excess of 1000 gross registered tonnage is in the region of 33000 (CIA 2008). If two-thirds are at sea at any time and, of these, half are in daylight, and typically each vessel could leave a foaming consistent with its wake around $30 \mathrm{~m}$ wide by $0.5 \mathrm{~km}$ in length, only $1 \mathrm{ppm}$ of illuminated ocean is modified.

Alternatively, one could imagine a system of wavepowered air compressors based on contemporary designs such as the Bobber (Stallard et al. 2008) for electrical wave-power generation, but outputting only compressed air and trailing a squid-like system of pipes fitted with bubble devices of the types described below. This arrangement could provide a more persistent foam if it was combined with local enhancement of nutrients to encourage the growth of marine organisms that excrete surfactants and viscosity modifiers to enhance the stability of foam. This may be one of the best methods to obtain long-term ocean albedo management, but of course, foam stabilisation would reduce the impact on marine cloud by reducing the production rate of CCN.

Recent work (Farook et al. 2007a,b, 2009a,b,c, Ahmad et al. 2008, Pancholi et al. 2008a,b, Stride et al. 2008, 2009) has helped to develop new methods for preparing bubble suspensions based on electrohydrodynamic processing and microfluidics. The former can generate $10^{9}$ bubbles $\min ^{-1}$ from a single nozzle and has been shown to produce coated bubbles in the 1 to $10 \mu \mathrm{m}$ diameter range with a high degree of predictability and control over size, size distribution and coating characteristics. The arrangement is shown in Fig. 2. Larger bubbles ( $>10 \mu \mathrm{m}$ in diameter) can also easily be generated using this technique. An even higher degree of control over bubble size and uniformity (<1\% polydispersivity) can be obtained using microfluidic techniques (Fig. 3), which are similarly capable of generating bubbles in the micrometre and millimetre size range. Thus, near monodisperse foams could be designed with a specific lifetime, size and hence optical scattering coefficient. The benefits of more conventional foam generation techniques such as sonication, which allows the preparation of bubbles (in the range $500 \mathrm{~nm}$ to $100 \mu \mathrm{m}$ ) with wider size distributions, may also be worthy of investigation, and comparison of microfluidic, coaxial electrohydrodynamic and sonication methods has already been made (Stride \& Edirisinghe 2009). The stability of such bubbles in seawater is strongly dependent on trace organic constituents. 
a

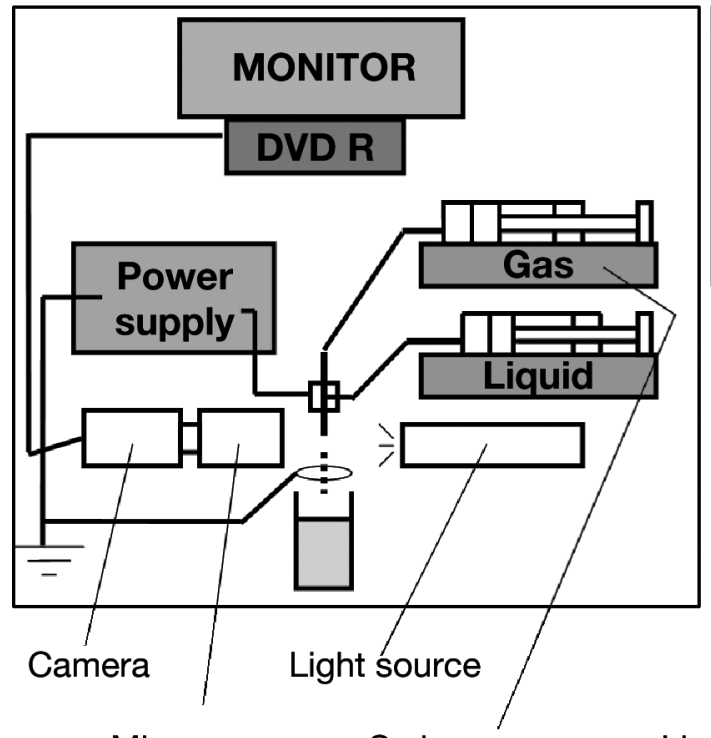

Microscope b

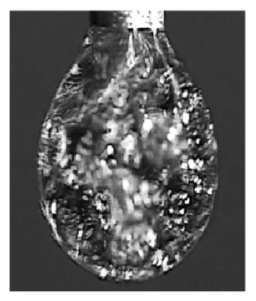

C
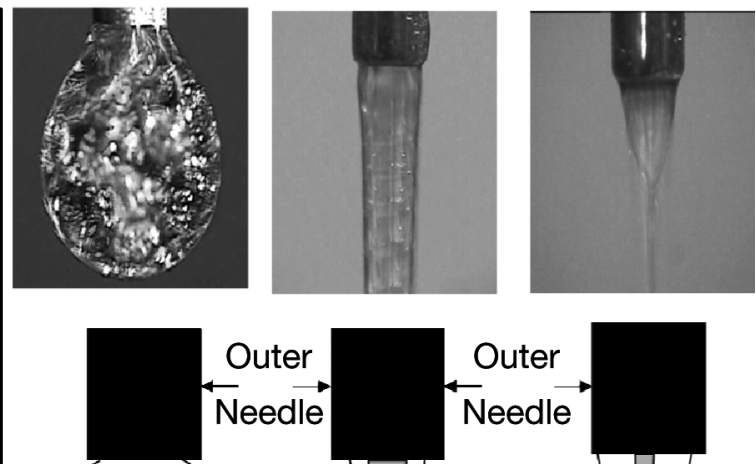

$\stackrel{\text { Outer }}{\text { Needle }}$

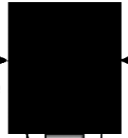

Needle

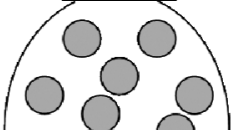

O

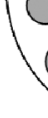

Liquid Meniscus
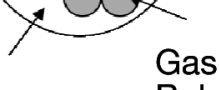

Gas

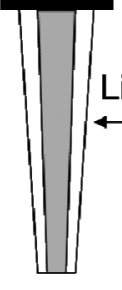

Liquid-Gas

$\leftarrow$ Cone $\rightarrow$
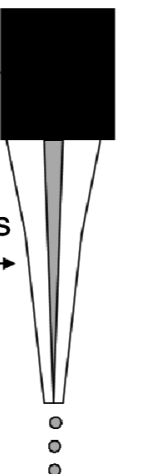

Syringe pumps

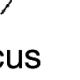

Fig. 2. Schematic diagram of the coaxial electrohydrodynamic atomisation method for bubble production showing: (a) apparatus equipped with DVD recorder (DVD R), and image and schematic of (b) bubble-dripping, (c) coning of the jet and (d) continuous microbubbling
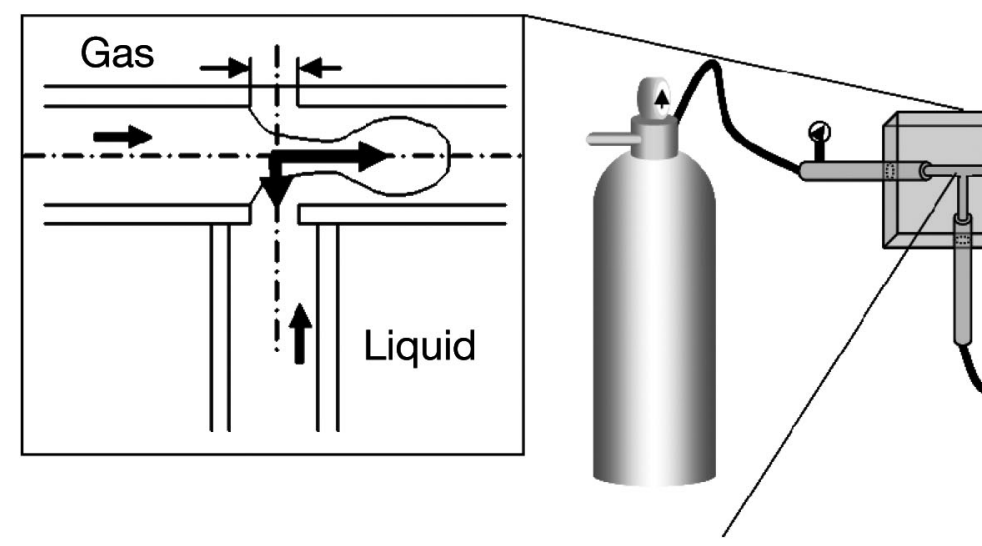
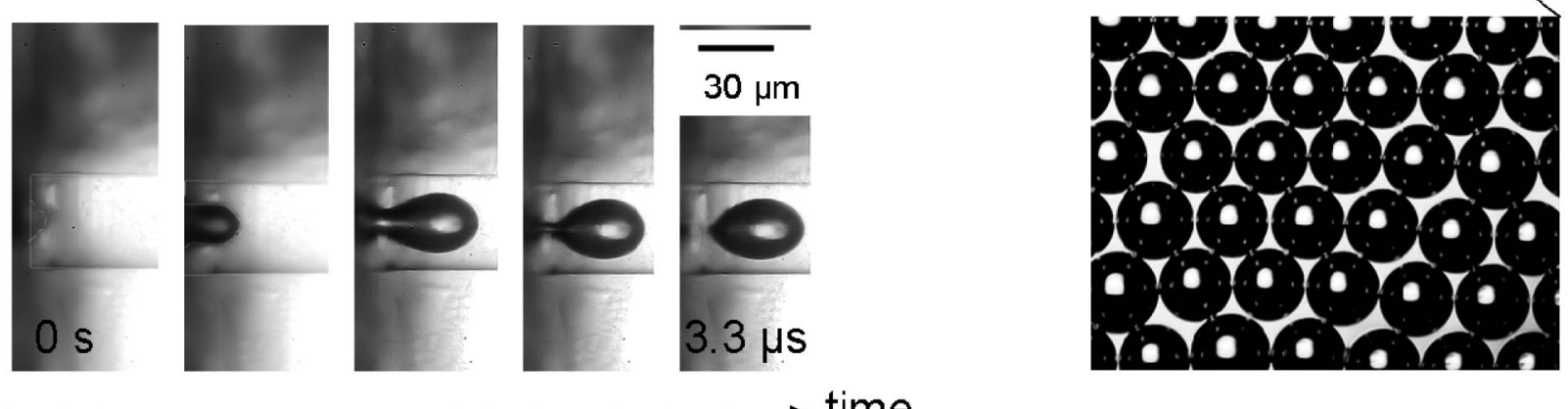

\section{time}

Fig. 3. Production of microbubbles at a T-junction showing the formation of a monodisperse raft of bubbles of $20 \mu \mathrm{m}$ diameter at a rate of $300000 \mathrm{~s}^{-1}$. Schematic and image of events at the junction (left) are accompanied by images of the bubbles in the outlet and the bubble assembly after collection (right) 
The first report of stable microbubbles in seawater (Johnson \& Cooke 1981) showed that there was little reduction in number after $80 \mathrm{ks}$.

\section{PROSPECTS}

There are of course, as with all climate interventions, potential side effects. The increase in surface albedo reduces the transmission of shorter wavelengths to lower ocean levels and might influence both the marine ecobalance and thermally driven ocean currents. In this context, an advantage of this method is that the ocean-going platforms could be moved continuously, perhaps informed by satellite, foam density and stability could be controlled and bubble generation could quickly be extinguished. The full effect of enhanced reflection of solar radiation from the ocean surface deserves to be explored in coupled climate models, in view of the likely simplicity of the engineering interventions compared with other geoengineering proposals. Furthermore, the best locations at which to deploy foamers with minimal side effects should be found and the maximum residence time in one place estimated. The chosen technique should provide for considerable positional maneuverability and control of bubble type providing a feedback loop possibly informed by satellite measurements such as temperature, algal proliferation and cloud cover. There is a need to produce some concept design studies of potential marine structures and/or devices to be towed by vessels to assess their likely energy demands and costs for the area coverage needed to obtain the desired forcing.

\section{LITERATURE CITED}

> Ahmad Z, Zhang HB, Farook U, Edirisinghe M, Stride E, Colombo P (2008) Generation of multilayered structures for biomedical applications using a novel tri-needle coaxial device and electrohydrodynamic flow. J R Soc Interface 5:1255-1261

Andreas EL, Monahan EC (2000) The role of whitecap bubbles in air-sea heat and moisture exchange. J Phys Oceanogr 30:433-442

Bala G (2009) Problems with geoengineering schemes to combat climate change. Curr Sci 96:41-48

Boulton-Stone JM, Blake JR (1993) Gas bubbles bursting at a free surface. J Fluid Mech 254:437-466

Bower K, Choularton T, Latham J, Sahraei J, Salter J (2006) Computational assessment of a proposed technique for global warming mitigation via albedo-enhancement of marine stratocumulus clouds. Atmos Res 82:328-336

Budyko MI (1982) The Earth's climate, past and future. Academic Press, New York

CIA (Central Intelligence Agency) (2008) CIA World Factbook. Skyhorse Publications, New York

> Costello A, Abbas M, Allen A, Ball S and others (2009) Managing the health effects of climate change. Lancet
373:1693-1733

Crutzen PJ (2006) Albedo enhancement by stratospheric sulphur injections: a contribution to resolve a policy dilemma. Clim Change 77:211-219

Daif A, Kamoun B, Mudry M (1991) Evaluation of wingsail interactions for windship propulsion. Eur J Mech B Fluids 10:185-206

Davies JA (1962) Albedo measurements over sub-arctic surfaces. McGill Sub-Arctic Res Pap 13:61-68

Early JT (1989) Space-based solar shield to offset greenhouse effect. J Br Interplanet Soc 42:567-569

Farook U, Stride E, Edirisinghe MJ, Moaleji R (2007a) Microbubbling by co-axial electrohydrodynamic atomization. Med Biol Eng Comput 45:781-789

Farook U, Zhang HB, Edirisinghe MJ, Stride E, Saffari N (2007b) Preparation of microbubble suspensions by coaxial electrohydrodynamic atomization. Med Eng Phys 29: 749-754

Farook U, Stride E, Edirisinghe MJ (2009a) Controlling size and size distribution of electrohydrodynamically prepared microbubbles. Bubble Sci Eng Technol 1:53-57

- Farook U, Stride E, Edirisinghe MJ (2009b) Stability of microbubbles prepared by co-axial electrohydrodynamic atomisation. Eur Biophys J 38:713-718

> Farook U, Stride E, Edirisinghe MJ (2009c) Preparation of suspensions of phospholipid-coated microbubbles by coaxial electrohydrodynamic atomization. J R Soc Interface 6: 271-277

Frouin R, Schwindling M, Deschamps PY (1996) Spectral reflectance of sea foam in the visible and near-infrared: in situ measurements and remote sensing implications. J Geophys Res 101:14361-14371

Gordon HR, Jacobs M (1977) Albedo of the ocean-atmosphere system: influence of sea foam. Appl Opt 16:2257-2260

Hamwey RM (2007) Active amplification of the terrestrial albedo to mitigate climate change; an exploratory study. Mitig Adapt Strategies Global Change 12:1381-1386

Heintzenberg J, Covert DC, van Dingenen R (2000) Size distribution and chemical composition of marine aerosols. Tellus B 52:1104-1122

Jaenicke R (1993) Tropospheric aerosols. In: Hobbs PV (ed) Aerosol-cloud-climate interactions. Academic Press, New York, p 1-33

Jin Z, Charlock TP, Rutledge K (2002) Analysis of broadband solar radiation and albedo over the ocean surface at COVE. J Atmos Ocean Technol 19:1585-1601

Jin Z, Charlock TP, Smith W, Rutledge K (2004) A parameterization of ocean surface albedo. Geophys Res Lett 31: L22301 doi:10.1029/2004GL021180

Johnson BD, Cooke RC (1981) Generation of stabilized microbubbles in seawater. Science 213:209-211

$>$ Keith DW (2000) Geoengineering the climate. Annu Rev Energy Environ 25:245-284

$>$ Koepke P (1984) Effective reflectance of oceanic whitecaps. Appl Opt 23:1816-1824

Kokhanovsky AA (2004) Spectral reflectance of whitecaps. J Geophys Res 109:C05021 doi:10.1029/2003JC002177

Latham J, Rasch P, Chen CC, Kettles L and others (2008) Global temperature stabilisation via controlled albedo enhancement of low level maritime clouds. Philos Trans R Soc Lond A 366:3969-3987

Morton O (2007) Is this what it takes to save the world? Nature 447:132-136

> O'Dowd CD, Smith MH, Consterdine IE, Lowe JA (1997) Marine aerosol, seasalt and the marine sulphur cycle: a short review. Atmos Environ 31:73-80

Pancholi K, Stride E, Edirisinghe M (2008a) Dynamics of 
bubble formation in highly viscous liquids. Langmuir 24: 4388-4393

Pancholi K, Stride E, Edirisinghe M (2008b) Generation of microbubbles for diagnostic and therapeutic applications using a novel device. J Drug Target 16:494-501

Payne RE (1972) Albedo of the sea surface. J Atmos Sci 29: 959-970

Salter S, Sortino G, Latham J (2008) Sea-going hardware for the cloud albedo method of reversing global warming. Philos Trans R Soc Lond A 366:3989-4006

Schneider SH (2008) Geoengineering: Could we or should we make it work? Philos Trans R Soc Lond A 366:3843-3862

Seifritz W (1989) Mirrors to halt global warming. Nature 340:603

Sellegri K, O'Dowd CD, Yoon YJ, Jennings SG, de Leeuw G (2006) Surfactants and submicron sea spray generation. J Geophys Res 111:D22215 doi:10.1029/2005JD006658

Shepherd J (ed) (2009) Geoengineering the climate: science, governance and uncertainty. The Royal Society, London

Stallard T, Stansby PK, Williamson AJ (2008) An experimental study of closely spaced point absorber arrays. Proc 18th Int Offshore Polar Eng Conf 1:417-424

Editorial responsibility: Mikhail Semenov,

Harpenden, UK
Stride E, Edirisinghe M (2009) Novel preparation techniques for controlling microbubble uniformity: a comparison. Med Biol Eng Comput 47:883-892

Stride E, Pancholi K, Edirisinghe MJ, Samarasinghe S (2008) Increasing the non-linear character of microbubble oscillations at low acoustic pressures. J R Soc Interface 5: 807-811

Sullivan GR, Bowman F, Farrell LP Jr, Gaffney PG II and others (2007) National security and the threat of climate change. Report of the Military Advisory Board, CNA Corporation, Alexandria, VA, p 1-63

Teller E, Wood L, Hyde R (1997) Global warming and ice ages. I. Prospects for physics-based modulation of global change. 22nd Annual International Seminar on Planetary Emergencies, Erice, Italy, 19-24 Aug 1997. Lawrence Livermore Labs, Berkeley, CA, p 1-18

Twomey S (1971) Radiative transfer: terrestrial clouds. J Quant Spectrosc Radiat Transf 11:779-783

Whitlock CH, Bartlett DS, Gurganus EA (1982) Sea foam reflectance and influence on optimum wavelength for remote sensing of ocean aerosols. Geophys Res Lett 9: $719-722$

Submitted: March 24, 2010; Accepted: May 20, 2010

Proofs received from author(s): June 29, 2010 